\title{
The Modified Block Iterative Algorithms for Asymptotically Relatively Nonexpansive Mappings and the System of Generalized Mixed Equilibrium Problems
}

\author{
Kriengsak Wattanawitoon ${ }^{1}$ and Poom Kumam ${ }^{2}$ \\ ${ }^{1}$ Department of Mathematics and Statistics, Faculty of Science and Agricultural Technology, Rajamangala \\ University of Technology Lanna Tak, Tak 63000, Thailand \\ ${ }^{2}$ Department of Mathematics, Faculty of Science, King Mongkut's University of Technology Thonburi \\ (KMUTT), Bangmod, Thrungkru, Bangkok 10140, Thailand
}

Correspondence should be addressed to Poom Kumam, poom.kum@kmutt.ac.th

Received 3 March 2012; Accepted 17 June 2012

Academic Editor: Hong-Kun Xu

Copyright (c) 2012 K. Wattanawitoon and P. Kumam. This is an open access article distributed under the Creative Commons Attribution License, which permits unrestricted use, distribution, and reproduction in any medium, provided the original work is properly cited.

The propose of this paper is to present a modified block iterative algorithm for finding a common element between the set of solutions of the fixed points of two countable families of asymptotically relatively nonexpansive mappings and the set of solution of the system of generalized mixed equilibrium problems in a uniformly smooth and uniformly convex Banach space. Our results extend many known recent results in the literature.

\section{Introduction}

The equilibrium problem theory provides a novel and unified treatment of a wide class of problems which arise in economics, finance, image reconstruction, ecology, transportation, networks, elasticity, and optimization, and it has been extended and generalized in many directions.

In the theory of equilibrium problems, the development of an efficient and implementable iterative algorithm is interesting and important. This theory combines theoretical and algorithmic advances with novel domain of applications. Analysis of these problems requires a blend of techniques from convex analysis, functional analysis, and numerical analysis. 
Let $E$ be a Banach space with norm $\|\cdot\|, C$ be a nonempty closed convex subset of $E$, and let $E^{*}$ denote the dual of $E$. Let $f_{i}: C \times C \rightarrow \mathbb{R}$ be a bifunction, $\psi_{i}: C \rightarrow \mathbb{R}$ be a real-valued function, where $\mathbb{R}$ is denoted by the set of real numbers, and $A_{i}: C \rightarrow E^{*}$ be a nonlinear mapping. The goal of the system of generalized mixed equilibrium problem is to find $u \in C$ such that

$$
\begin{array}{cc}
f_{1}(u, y)+\left\langle A_{1} u, y-u\right\rangle+\psi_{1}(y)-\psi_{1}(u) \geq 0, & \forall y \in C, \\
f_{2}(u, y)+\left\langle A_{2} u, y-u\right\rangle+\psi_{2}(y)-\psi_{2}(u) \geq 0, & \forall y \in C, \\
\vdots & \\
f_{N}(u, y)+\left\langle A_{N} u, y-u\right\rangle+\psi_{N}(y)-\psi_{N}(u) \geq 0, & \forall y \in C .
\end{array}
$$

If $f_{i}=f, A_{i}=A$, and $\psi_{i}=\psi$, the problem (1.1) is reduced to the generalized mixed equilibrium problem, denoted by $\operatorname{GEMP}(f, A, \psi)$, to find $u \in C$ such that

$$
f(u, y)+\langle A u, y-u\rangle+\psi(y)-\psi(u) \geq 0, \quad \forall y \in C .
$$

The set of solutions to (1.2) is denoted by $\Omega$, that is,

$$
\Omega=\{x \in C: f(u, y)+\langle A u, y-u\rangle+\varphi(y)-\varphi(u) \geq 0, \forall y \in C\}
$$

If $A=0$, the problem (1.2) is reduced to the mixed equilibrium problem for $f$, denoted by $\operatorname{MEP}(f, \psi)$, to find $u \in C$ such that

$$
f(u, y)+\psi(y)-\psi(u) \geq 0, \quad \forall y \in C
$$

If $f \equiv 0$, the problem (1.2) is reduced to the mixed variational inequality of Browder type, denoted by $\operatorname{VI}(C, A, \psi)$, is to find $u \in C$ such that

$$
\langle A u, y-u\rangle+\psi(y)-\psi(u) \geq 0, \quad \forall y \in C
$$

If $A=0$ and $\psi=0$, the problem (1.2) is reduced to the equilibrium problem for $f$, denoted by $\mathrm{EP}(f)$, to find $u \in C$ such that

$$
f(u, y) \geq 0, \quad \forall y \in C
$$

The above formulation (1.6) was shown in [1] to cover monotone inclusion problems, saddle-point problems, variational inequality problems, minimization problems, vector equilibrium problems, and Nash equilibria in noncooperative games. In addition, there are several other problems, for example, the complementarity problem, fixed-point problem, and optimization problem, which can also be written in the form of an $\operatorname{EP}(f)$. In other words, the $\mathrm{EP}(f)$ is a unifying model for several problems arising in physics, engineering, science, economics, and so forth. In the last two decades, many papers have appeared in the literature 
on the existence of solutions to $\mathrm{EP}(f)$; see, for example [1-4] and references therein. Some solution methods have been proposed to solve the $\operatorname{EP}(f)$; see, for example, [2, 4-15] and references therein. In 2005, Combettes and Hirstoaga [5] introduced an iterative scheme of finding the best approximation to the initial data when $\operatorname{EP}(f)$ is nonempty, and they also proved a strong convergence theorem.

A Banach space $E$ is said to be strictly convex if $\|(x+y) / 2\|<1$ for all $x, y \in E$ with $\|x\|=\|y\|=1$ and $x \neq y$. Let $U=\{x \in E:\|x\|=1\}$ be the unit sphere of $E$. Then the Banach space $E$ is said to be smooth, provided

$$
\lim _{t \rightarrow 0} \frac{\|x+t y\|-\|x\|}{t}
$$

exists for each $x, y \in U$. It is also said to be uniformly smooth if the limit is attained uniformly for $x, y \in E$. The modulus of convexity of $E$ is the function $\delta:[0,2] \rightarrow[0,1]$ defined by

$$
\delta(\varepsilon)=\inf \left\{1-\left\|\frac{x+y}{2}\right\|: x, y \in E,\|x\|=\|y\|=1,\|x-y\| \geq \varepsilon\right\}
$$

A Banach space $E$ is uniformly convex, if and only if $\delta(\varepsilon)>0$ for all $\varepsilon \in(0,2]$.

Let $E$ be a Banach space, $C$ be a closed convex subset of $E$, a mapping $T: C \rightarrow C$ is said to be nonexpansive if

$$
\|T x-T y\| \leq\|x-y\|
$$

for all $x, y \in C$. We denote by $F(T)$ the set of fixed points of $T$. If $C$ is a bounded closed convex set and $T$ is a nonexpansive mapping of $C$ into itself, then $F(T)$ is nonempty (see [16]). A point $p$ in $C$ is said to be an asymptotic fixed point of $T$ [17] if $C$ contains a sequence $\left\{x_{n}\right\}$ which converges weakly to $p$ such that $\lim _{n \rightarrow \infty}\left\|x_{n}-T x_{n}\right\|=0$. The set of asymptotic fixed points of $T$ will be denoted by $\widetilde{F(T)}$. A point $p \in C$ is said to be a strong asymptotic fixed point of $T$, if there exists a sequence $\left\{x_{n}\right\} \subset C$ such that $x_{n} \rightarrow p$ and $\left\|x_{n}-T x_{n}\right\| \rightarrow 0$. The set of strong asymptotic fixed points of $T$ will be denoted by $\widehat{F}(T)$. A mapping $T$ from $C$ into itself is said to be relatively nonexpansive [18-20] if $\widetilde{F(T)}=F(T)$ and $\phi(p, T x) \leq \phi(p, x)$ for all $x \in C$ and $p \in F(T)$. The asymptotic behavior of a relatively nonexpansive mapping was studied in [21, 22]. $T$ is said to be $\phi$-nonexpansive, if $\phi(T x, T y) \leq \phi(x, y)$ for $x, y \in C$. $T$ is said to be quas- $\phi$-nonexpansive if $F(T) \neq \emptyset$ and $\phi(p, T x) \leq \phi(p, x)$ for $x \in C$ and $p \in F(T)$. A mapping $T$ is said to be asymptotically relatively nonexpansive, if $F(T) \neq \emptyset$, and there exists a real sequence $\left\{k_{n}\right\} \subset[1, \infty)$ with $k_{n} \rightarrow 1$ such that $\phi\left(p, T^{n} x\right) \leq k_{n} \phi(p, x)$, for all $n \geq 1, x \in C$, and $p \in F(T) .\left\{T_{n}\right\}_{n=0}^{\infty}$ is said to be a countable family of weak relatively nonexpansive mappings [23] if the following conditions are satisfied:

(i) $F\left(\left\{T_{n}\right\}_{n=0}^{\infty}\right) \neq \emptyset$;

(ii) $\phi\left(u, T_{n} x\right) \leq \phi(u, x)$, for all $u \in F\left(T_{n}\right), x \in C, n \geq 0$;

(iii) $\widehat{F}\left(\left\{T_{n}\right\}_{n=0}^{\infty}\right)=\bigcap_{n=0}^{\infty} F\left(T_{n}\right)$. 
A mapping $T: C \rightarrow C$ is said to be uniformly L-Lipschitz continuous, if there exists a constant $L>0$ such that

$$
\left\|T^{n} x-T^{n} y\right\| \leq L\|x-y\|, \quad \forall x, y \in C, \forall n \geq 1 .
$$

A mapping $T: C \rightarrow C$ is said to be closed if for any sequence $\left\{x_{n}\right\} \subset C$ with $x_{n} \rightarrow x$ and $T x_{n} \rightarrow y$, then $T x=y$. Let $\left\{T_{i}\right\}_{i=1}^{\infty}: C \rightarrow C$ be a sequence of mappings. $\left\{T_{i}\right\}_{i=1}^{\infty}$ is said to be a countable family of uniformly asymptotically relatively nonexpansive mappings, if $\cap_{n=1}^{\infty} F\left(T_{n}\right) \neq \emptyset$, and there exists a sequence $\left\{k_{n}\right\} \subset[1, \infty)$ with $k_{n} \rightarrow 1$ such that for each $i>1$

$$
\phi\left(p, T_{i}^{n} x\right) \leq k_{n} \phi(p, x), \quad \forall p \in \bigcap_{n=1}^{\infty} F\left(T_{n}\right), x \in C, \forall n \geq 1
$$

In 2009, Petrot et al. [24], introduced a hybrid projection method for approximating a common element of the set of solutions of fixed points of hemirelatively nonexpansive (or quasi- $\phi$-nonexpansive) mappings in a uniformly convex and uniformly smooth Banach space:

$$
\begin{gathered}
x_{0} \in C, \quad C_{0}=C, \\
y_{n}=J^{-1}\left(\alpha_{n} J x_{n}+\left(1-\alpha_{n}\right) J T_{n} z_{n}\right), \\
z_{n}=J^{-1}\left(\beta_{n} J x_{n}+\left(1-\beta_{n}\right) J T_{n} x_{n}\right), \\
C_{n+1}=\left\{v \in C_{n}: \phi\left(v, y_{n}\right) \leq \phi\left(v, x_{n}\right)\right\}, \\
x_{n+1}=\prod_{C_{n+1}}\left(x_{0}\right) .
\end{gathered}
$$

They proved that the sequence $\left\{x_{n}\right\}$ converges strongly to $p \in F(T)$, where $p \in \Pi_{F(T)} x$ and $\Pi_{C}$ is the generalized projection from $E$ onto $F(T)$. Kumam and Wattanawitoon [25], introduced a hybrid iterative scheme for finding a common element of the set of common fixed points of two quasi- $\phi$-nonexpansive mappings and the set of solutions of an equilibrium problem in Banach spaces, by the following manner:

$$
\begin{gathered}
x_{0} \in C, \quad C_{0}=C \\
y_{n}=J^{-1}\left(\alpha_{n} J x_{n}+\left(1-\alpha_{n}\right) J S z_{n}\right), \\
z_{n}=J^{-1}\left(\beta_{n} J x_{n}+\left(1-\beta_{n}\right) J T x_{n}\right), \\
u_{n} \in C \text { such that } f\left(u_{n}, y\right)+\frac{1}{r_{n}}\left\langle y-u_{n} J u_{n}-J y_{n}\right\rangle \geq 0, \quad \forall y \in C, \\
C_{n+1}=\left\{z \in C_{n}: \phi\left(z, u_{n}\right) \leq \phi\left(z, x_{n}\right)\right\}, \\
x_{n+1}=\prod_{C_{n+1}}\left(x_{0}\right) .
\end{gathered}
$$


They proved that the sequence $\left\{x_{n}\right\}$ converges strongly to $p \in F(T) \cap F(S) \cap \operatorname{EP}(f)$, where $p \in \Pi_{F(T) \cap F(S) \cap E P(f)} x$ under the assumptions (C1) $\limsup _{n \rightarrow \infty} \alpha_{n}<1$, (C2) $\lim _{n \rightarrow \infty} \beta_{n}<1$, and (C3) $\liminf \operatorname{in}_{n \rightarrow \infty}\left(1-\alpha_{n}\right) \beta_{n}\left(1-\beta_{n}\right)>0$.

Recently, Chang et al. [26], introduced the modified block iterative method to propose an algorithm for solving the convex feasibility problems for an infinite family of quasi- $\phi$ asymptotically nonexpansive mappings,

$$
\begin{gathered}
x_{0} \in C \text { chosen arbitrary, } \quad C_{0}=C, \\
y_{n}=J^{-1}\left(\alpha_{n, 0} J x_{n}+\sum_{i=1}^{\infty} \alpha_{n, i} J S_{i}^{n} x_{n}\right), \\
C_{n+1}=\left\{v \in C_{n}: \phi\left(v, y_{n}\right) \leq \phi\left(v, x_{n}\right)+\xi_{n}\right\}, \\
x_{n+1}=\prod_{C_{n+1}} x_{0}, \quad \forall n \geq 0,
\end{gathered}
$$

where $\xi_{n}=\sup _{u \in F}\left(k_{n}-1\right) \phi\left(u, x_{n}\right)$. Then, they proved that under appropriate control conditions the sequence $\left\{x_{n}\right\}$ converges strongly to $\prod_{\bigcap_{n=1}^{\infty}} F\left(S_{i}\right) x_{0}$.

Very recently, Tan and Chang [27], introduced a new hybrid iterative scheme for finding a common element between set of solutions for a system of generalized mixed equilibrium problems, set of common fixed points of a family of quasi- $\phi$-asymptotically nonexpansive mappings (which is more general than quasi- $\phi$-nonexpansive mappings), and null spaces of finite family of $\gamma$-inverse strongly monotone mappings in a 2-uniformly convex and uniformly smooth real Banach space.

In this paper, motivated and inspired by Petrot et al. [24], Kumam and Wattanawitoon [25], Chang et al. [26], and Tan and Chang [27], we introduce the new hybrid block algorithm for two countable families of closed and uniformly Lipschitz continuous and uniformly asymptotically relatively nonexpansive mappings in a Banach space. Let $\left\{x_{n}\right\}$ be a sequence defined by $x_{0} \in C, C_{0}=C$ and

$$
\begin{gathered}
y_{n}=J^{-1}\left(\beta_{n, 0} J\left(x_{n}\right)+\sum_{i=1}^{\infty} \beta_{n, i} J\left(T_{i}^{n} x_{n}\right)\right), \\
z_{n}=J^{-1}\left(\alpha_{n, 0} J\left(x_{n}\right)+\sum_{i=1}^{\infty} \alpha_{n, i} J\left(S_{i}^{n} y_{n}\right)\right), \\
C_{n+1}^{(i)}=\left\{K_{f_{i}, r_{i}} K_{f_{i-1}, r_{i-1}} \cdots K_{f_{1}, r_{1}}\left(z_{n}\right), \quad i=1,2, \ldots, N,\right. \\
\left.z \in C_{n}: \max _{i=1,2, \ldots, N} \phi\left(z, u_{n}^{(i)}\right) \leq \phi\left(z, x_{n}\right)+\theta_{n}, \phi\left(z, y_{n}\right) \leq \phi\left(z, x_{n}\right)+\xi_{n}\right\}, \\
x_{n+1}=\prod_{C_{n+1}} x_{0}, \quad \forall n \geq 0 .
\end{gathered}
$$

Under appropriate conditions, we will prove that the sequence $\left\{x_{n}\right\}$ generated by algorithms (1.15) converges strongly to the point $\prod_{\left(\cap_{i=1}^{N} \Omega_{i}\right) \cap\left(\cap_{i=1}^{\infty} F\left(T_{i}\right)\right) \cap\left(\cap_{i=1}^{\infty} F\left(S_{i}\right)\right)} x_{0}$. Our results extend many known recent results in the literature. 


\section{Preliminaries}

Let $E$ be a real Banach space with norm $\|\cdot\|$, and let $J$ be the normalized duality mapping from $E$ into $2^{E^{*}}$ given by

$$
J x=\left\{x^{*} \in E^{*}:\left\langle x, x^{*}\right\rangle=\|x\|\left\|x^{*}\right\|,\|x\|=\left\|x^{*}\right\|\right\}
$$

for all $x \in E$, where $E^{*}$ denotes the dual space of $E$ and $\langle\cdot, \cdot\rangle$ the generalized duality pairing between $E$ and $E^{*}$. It is also known that if $E$ is uniformly smooth, then $J$ is uniformly normto-norm continuous on each bounded subset of $E$.

We know the following (see [28, 29]):

(i) if $E$ is smooth, then $J$ is single valued;

(ii) if $E$ is strictly convex, then $J$ is one-to-one and $\left\langle x-y, x^{*}-y^{*}\right\rangle>0$ holds for all $\left(x, x^{*}\right),\left(y, y^{*}\right) \in J$ with $x \neq y$;

(iii) if $E$ is reflexive, then $J$ is surjective;

(iv) if $E$ is uniformly convex, then it is reflexive;

(v) if $E$ is a reflexive and strictly convex, then $J^{-1}$ is norm-weak-continuous;

(vi) $E$ is uniformly smooth if and only if $E^{*}$ is uniformly convex;

(vii) if $E^{*}$ is uniformly convex, then $J$ is uniformly norm-to-norm continuous on each bounded subset of $E$;

(viii) each uniformly convex Banach space $E$ has the Kadec-Klee property, that is, for any sequence $\left\{x_{n}\right\} \subset E$, if $x_{n} \rightarrow x \in E$ and $\left\|x_{n}\right\| \rightarrow\|x\|$, then $x_{n} \rightarrow x$.

Let $E$ be a smooth, strictly convex, and reflexive Banach space, and let $C$ be a nonempty closed convex subset of $E$. Throughout this paper, we denote by $\phi$ the function defined by

$$
\phi(x, y)=\|x\|^{2}-2\langle x, J y\rangle+\|y\|^{2}, \quad \text { for } x, y \in E
$$

Following Alber [30], the generalized projection $\Pi_{C}: E \rightarrow C$ is a map that assigns to an arbitrary point $x \in E$ the minimum point of the function $\phi(x, y)$, that is, $\Pi_{C} x=\bar{x}$, where $\bar{x}$ is the solution to the minimization problem

$$
\phi(\bar{x}, x)=\inf _{y \in C} \phi(y, x) .
$$

Existence and uniqueness of the operator $\Pi_{C}$ follows from the properties of the functional $\phi(x, y)$ and strict monotonicity of the mapping $J$. It is obvious from the definition of function $\phi$ that (see [30])

$$
(\|y\|-\|x\|)^{2} \leq \phi(y, x) \leq(\|y\|+\|x\|)^{2}, \quad \forall x, y \in E .
$$

If $E$ is a Hilbert space, then $\phi(x, y)=\|x-y\|^{2}$.

If $E$ is a reflexive, strictly convex, and smooth Banach space, then for $x, y \in E, \phi(x, y)=$ 0 if and only if $x=y$. It is sufficient to show that if $\phi(x, y)=0$, then $x=y$. From (2.4), we 
have $\|x\|=\|y\|$. This implies that $\langle x, J y\rangle=\|x\|^{2}=\|J y\|^{2}$. From the definition of $J$, one has $J x=J y$. Therefore, we have $x=y$; see [28, 29] for more details.

We also need the following lemmas for the proof of our main results.

Lemma 2.1 (see Kamimura and Takahashi [31]). Let E be a uniformly convex and smooth real Banach space, and let $\left\{x_{n}\right\},\left\{y_{n}\right\}$ be two sequences of $E$. If $\phi\left(x_{n}, y_{n}\right) \rightarrow 0$ and either $\left\{x_{n}\right\}$ or $\left\{y_{n}\right\}$ is bounded, then $\left\|x_{n}-y_{n}\right\| \rightarrow 0$.

Lemma 2.2 (see Alber [30]). Let $C$ be a nonempty closed convex subset of a smooth Banach space $E$ and $x \in E$. Then, $x_{0}=\Pi_{C} x$ if and only if

$$
\left\langle x_{0}-y_{1} J x-J x_{0}\right\rangle \geq 0, \quad \forall y \in C
$$

Lemma 2.3 (see Alber [30]). Let E be a reflexive, strictly convex, and smooth Banach space, let $C$ be a nonempty closed convex subset of $E$, and let $x \in E$. Then

$$
\phi\left(y, \Pi_{C} x\right)+\phi\left(\Pi_{C} x, x\right) \leq \phi(y, x), \quad \forall y \in C .
$$

Lemma 2.4 (see Chang et al. [26]). Let E be a uniformly convex Banach space, $r>0$ a positive number, and $B_{r}(0)$ a closed ball of $E$. Then, for any given sequence $\left\{x_{i}\right\}_{i=1}^{\infty} \subset B_{r}(0)$ and for any given sequence $\left\{\lambda_{i}\right\}_{i=1}^{\infty}$ of positive number with $\sum_{n=1}^{\infty} \lambda_{n}=1$, there exists a continuous, strictly increasing, and convex function $g:[0,2 r) \rightarrow[0, \infty)$ with $g(0)=0$ such that for any positive integers $i, j$ with $i<j$,

$$
\left\|\sum_{n=1}^{\infty} \lambda_{n} x_{n}\right\|^{2} \leq \sum_{n=1}^{\infty} \lambda_{n}\left\|x_{n}\right\|^{2}-\lambda_{i} \lambda_{j} g\left(\left\|x_{i}-x_{j}\right\|\right) .
$$

Lemma 2.5 (see Chang et al. [26]). Let $E$ be a real uniformly smooth and strictly convex Banach space with Kadec-Klee property, and $C$ be a nonempty closed convex subset of $E$. Let $T: C \rightarrow C$ be a closed and asymptotically relatively nonexpansive mapping with a sequence $\left\{k_{n}\right\} \subset[1, \infty), k_{n} \rightarrow 1$. Then $F(T)$ is closed and convex subset of $C$.

For solving the generalized mixed equilibrium problem (or a system of generalized mixed equilibrium problem), let us assume that the bifunction $f: C \times C \rightarrow \mathbb{R}$ and $\psi: C \rightarrow \mathbb{R}$ is convex and lower semicontinuous satisfies the following conditions:

(A1) $f(x, x)=0$ for all $x \in C$;

(A2) $f$ is monotone, that is, $f(x, y)+f(y, x) \leq 0$ for all $x, y \in C$;

(A3) for each $x, y, z \in C$,

$$
\limsup _{t \downarrow 0} f(t z+(1-t) x, y) \leq f(x, y)
$$

(A4) for each $x \in C, y \mapsto f(x, y)$ is convex and lower semicontinuous. 
Lemma 2.6 (see Chang et al. [26]). Let $C$ be a closed convex subset of a smooth, strictly convex, and reflexive Banach space $E$. Let $A: C \rightarrow E^{*}$ be a continuous and monotone mapping, $\psi: C \rightarrow \mathbb{R}$ is convex and lower semicontinuous and $f$ be a bifunction from $C \times C$ to $\mathbb{R}$ satisfying (A1)-(A4). For $r>0$ and $x \in E$, then there exists $u \in C$ such that

$$
f(u, y)+\langle A u, y-u\rangle+\psi(y)-\psi(u)+\frac{1}{r}\langle y-u, J u-J x\rangle \geq 0, \quad \forall y \in C
$$

Define a mapping $K_{f, r}: C \rightarrow C$ as follows:

$$
K_{f, r}(x)=\left\{u \in C: f(u, y)+\langle A u, y-u\rangle+\psi(y)-\psi(u)+\frac{1}{r}\langle y-u, J u-J x\rangle \geq 0, \forall y \in C\right\}
$$

for all $x \in E$. Then, the following hold:

(i) $K_{f, r}$ is singlevalued;

(ii) $K_{f, r}$ is firmly nonexpansive, that is, for all $x, y \in E,\left\langle K_{f, r} x-K_{f, r} y, J K_{f, r} x-J K_{f, r} y\right\rangle \leq$ $\left\langle K_{f, r} x-K_{f, r} y, J x-J y\right\rangle$;

(iii) $F\left(K_{f, r}\right)=\widetilde{F\left(K_{f, r}\right)}$;

(iv) $u \in C$ is a solution of variational equation (2.9) if and only if $u \in C$ is a fixed point of $K_{f, r}$;

(v) $F\left(K_{f, r}\right)=\Omega$;

(vi) $\Omega$ is closed and convex;

(vii) $\phi\left(p, K_{f, r} z\right)+\phi\left(K_{f, r} z, z\right) \leq \phi(p, z)$, for all $p \in F\left(K_{f, r}\right), z \in E$.

\section{Main Results}

Theorem 3.1. Let $E$ be a uniformly smooth and uniformly convex Banach space, let $C$ be a nonempty, closed, and convex subset of $E$. Let $A_{i}: C \rightarrow E^{*}$ be a continuous and monotone mapping, $\psi_{i}: C \rightarrow \mathbb{R}$ be a lower semi-continuous and convex function, $f_{i}$ be a bifunction from $C \times C$ to $\mathbb{R}$ satisfying (A1)-(A4), $K_{f_{i}, r_{i}}$ is the mapping defined by (2.10) where $r_{i} \geq r>0$, and let $\left\{T_{i}\right\}_{i=1}^{\infty}$, $\left\{S_{i}\right\}_{i=1}^{\infty}$ be countable families of closed and uniformly $L_{i}, \mu_{i}$-Lipschitz continuous and asymptotically relatively nonexpansive mapping with sequence $\left\{k_{n}\right\},\left\{\zeta_{n}\right\} \subset[1, \infty) ; k_{n} \rightarrow 1, \zeta_{n} \rightarrow 1$ such that 
$\mathcal{F}:=\left(\cap_{i=1}^{N} \Omega_{i}\right) \cap\left(\cap_{i=1}^{\infty} F\left(T_{i}\right)\right) \cap\left(\cap_{i=1}^{\infty} F\left(S_{i}\right)\right) \neq \emptyset$. Let $\left\{x_{n}\right\}$ be a sequence generated by $x_{0} \in C$ and $C_{0}=C$,

$$
\begin{gathered}
y_{n}=J^{-1}\left(\beta_{n, 0} J\left(x_{n}\right)+\sum_{i=1}^{\infty} \beta_{n, i} J\left(T_{i}^{n} x_{n}\right)\right), \\
z_{n}=J^{-1}\left(\alpha_{n, 0} J\left(x_{n}\right)+\sum_{i=1}^{\infty} \alpha_{n, i} J\left(S_{i}^{n} y_{n}\right)\right), \\
u_{n}^{(i)}=K_{f_{i}, r_{i}} K_{f_{i-1}, r_{i-1}} \cdots K_{f_{1}, r_{1}}\left(z_{n}\right), \quad i=1,2, \ldots, N, \\
C_{n+1}=\left\{z \in C_{n}: \max _{i=1,2, \ldots, N} \phi\left(z, u_{n}^{(i)}\right) \leq \phi\left(z, x_{n}\right)+\theta_{n}, \phi\left(z, y_{n}\right) \leq \phi\left(z, x_{n}\right)+\xi_{n}\right\}, \\
x_{n+1}=\prod_{C_{n+1}} x_{0}, \quad \forall n \geq 0,
\end{gathered}
$$

where $\xi_{n}=\sup _{p \in \mathcal{F}}\left(k_{n}-1\right) \phi\left(p, x_{n}\right), \theta_{n}=\delta_{n}+\xi_{n} \zeta_{n}$, and $\delta_{n}=\sup _{p \in \mathcal{F}}\left(\zeta_{n}-1\right) \phi\left(p, x_{n}\right)$. The coefficient sequences $\left\{\alpha_{n, i}\right\}$ and $\left\{\beta_{n, i}\right\} \subset[0,1]$ satisfy the following:

(i) $\sum_{i=0}^{\infty} \alpha_{n, i}=1$;

(ii) $\sum_{i=0}^{\infty} \beta_{n, i}=1$;

(iii) $\liminf \operatorname{in}_{n \rightarrow \infty} \alpha_{n, 0} \alpha_{n, i}>0$, for all $i \geq 1$;

(iv) $\liminf _{n \rightarrow \infty} \beta_{n, 0} \beta_{n, i}>0$, for all $i \geq 1$,

$\Omega_{i}, i=1,2, \ldots, N$ is the set of solutions to the following generalized mixed equilibrium problem:

$$
f_{i}(z, y)+\left\langle A_{i} z, y-z\right\rangle+\psi_{i}(y)-\psi_{i}(z) \geq 0, \quad \forall y \in C, i=1,2, \ldots, N
$$

Then the sequence $\left\{x_{n}\right\}$ converges strongly to $\Pi_{\mp} x_{0}$.

Proof. We first show that $C_{n}$, for all $n \geq 0$ is closed and convex. Clearly $C_{0}=C$ is closed and convex. Suppose that $C_{k}$ is closed and convex for some $k>1$. For each $z \in C_{k}$, we see that $\phi\left(z, u_{k}^{(i)}\right) \leq \phi\left(z, x_{k}\right)$ is equivalent to

$$
2\left(\left\langle z, x_{k}\right\rangle-\left\langle z, u_{k}^{(i)}\right\rangle\right) \leq\left\|x_{k}\right\|^{2}-\left\|u_{k}^{(i)}\right\|^{2}
$$

By the set of $C_{k+1}$, we have

$$
\begin{aligned}
C_{n+1} & =\left\{z \in C_{n}: \max _{i=1,2, \ldots, N} \phi\left(z, u_{n}^{(i)}\right) \leq \phi\left(z, x_{n}\right)+\theta_{n}\right\} \\
& =\bigcap_{i=1}^{N}\left\{z \in C: \phi\left(z, u_{n}^{(i)}\right) \leq \phi\left(z, x_{n}\right)+\theta_{n}\right\} .
\end{aligned}
$$

Hence, $C_{n+1}$ is also closed and convex. 
By taking $\Theta_{n}^{j}=K_{r_{i}, f_{i}} K_{r_{j-1}, f_{j-1}} \cdots K_{r_{1}, f_{1}}$ for any $j \in\{1,2, \ldots, i\}$ and $\Theta_{n}^{0}=I$ for all $n \geq 1$. We note that $u_{n}^{(i)}=\Theta_{n}^{i} z_{n}$.

Next, we show that $\mathcal{F} \subset C_{n}$, for all $n \geq 1$. For $n \geq 1$, we have $\mathcal{F} \subset C=C_{1}$. For any given $p \in \mathcal{F}:=\left(\cap_{i=1}^{N} \Omega_{i}\right) \cap\left(\cap_{i=1}^{\infty} F\left(T_{i}\right)\right) \cap\left(\cap_{i=1}^{\infty} F\left(S_{i}\right)\right)$. By (3.1) and Lemma 2.4, we have

$$
\begin{aligned}
& \phi\left(p, y_{n}\right)=\phi\left(p, J^{-1}\left(\sum_{i=0}^{\infty} \beta_{n, i} J T_{i}^{n} x_{n}\right)\right) \\
& =\|p\|^{2}-\sum_{i=0}^{\infty} \beta_{n, i} 2\left\langle p, J T_{i}^{n} x_{n}\right\rangle+\left\|\sum_{i=0}^{\infty} \beta_{n, i} J T_{i}^{n} x_{n}\right\|^{2} \\
& \leq\|p\|^{2}-\sum_{i=0}^{\infty} \beta_{n, i} 2\left\langle p, J T_{i}^{n} x_{n}\right\rangle+\sum_{i=0}^{\infty} \beta_{n, i}\left\|J T_{i}^{n} x_{n}\right\|^{2}-\beta_{n, 0} \beta_{n, i} g\left(\left\|J T_{0}^{n} x_{n}-J T_{i}^{n} x_{n}\right\|\right) \\
& =\|p\|^{2}-\sum_{i=0}^{\infty} \beta_{n, i} 2\left\langle p, J T_{i}^{n} x_{n}\right\rangle+\sum_{i=0}^{\infty} \beta_{n, i}\left\|T_{i}^{n} x_{n}\right\|^{2}-\beta_{n, 0} \beta_{n, i} g\left(\left\|J x_{n}-J T_{i}^{n} x_{n}\right\|\right) \\
& =\sum_{i=0}^{\infty} \beta_{n, i} \phi\left(p, T_{i}^{n} x_{n}\right)-\beta_{n, 0} \beta_{n, i} g\left(\left\|J x_{n}-J T_{i}^{n} x_{n}\right\|\right) \\
& \leq k_{n} \phi\left(p, x_{n}\right)-\beta_{n, 0} \beta_{n, i} g\left(\left\|J x_{n}-J T_{i}^{n} x_{n}\right\|\right) \\
& \leq \phi\left(p, x_{n}\right)+\sup _{p \in F}\left(k_{n}-1\right) \phi\left(p, x_{n}\right)-\beta_{n, 0} \beta_{n, i} g\left(\left\|J x_{n}-J T_{i}^{n} x_{n}\right\|\right) \\
& \leq \phi\left(p, x_{n}\right)+\xi_{n}-\beta_{n, 0} \beta_{n, i} g\left(\left\|J x_{n}-J T_{i}^{n} x_{n}\right\|\right) \\
& \leq \phi\left(p, x_{n}\right)+\xi_{n}
\end{aligned}
$$

where $\xi_{n}=\sup _{p \in \mathcal{F}}\left(k_{n}-1\right) \phi\left(p, x_{n}\right)$.

By (3.1) and (3.5), we note that

$$
\begin{aligned}
\phi\left(p, u_{n}^{(i)}\right)= & \phi\left(p, \Theta_{n}^{i} z_{n}\right) \\
\leq & \phi\left(p, z_{n}\right) \\
\leq & \phi\left(p, J^{-1}\left(\alpha_{n, 0} J x_{n}+\sum_{i=1}^{\infty} J S_{i}^{n} y_{n}\right)\right) \\
= & \|p\|^{2}-2\left\langle p, \alpha_{n, 0} J x_{n}+\sum_{i=1}^{\infty} J S_{i}^{n} y_{n}\right\rangle+\left\|\alpha_{n, 0} J x_{n}+\sum_{i=1}^{\infty} J S_{i}^{n} y_{n}\right\|^{2} \\
\leq & \|p\|^{2}-2 \alpha_{n, 0}\left\langle p, J x_{n}\right\rangle-2 \sum_{i=1}^{\infty} \alpha_{n, i}\left\langle p, J S_{i}^{n} y_{n}\right\rangle+\alpha_{n, 0}\left\|x_{n}\right\|^{2}+\sum_{i=1}^{\infty}\left\|S_{i}^{n} y_{n}\right\|^{2} \\
& -\alpha_{n, 0} \alpha_{n, i} g\left\|J x_{n}-J S_{i}^{n} y_{n}\right\|
\end{aligned}
$$


Journal of Applied Mathematics

$$
\begin{aligned}
& \leq \alpha_{n, 0} \phi\left(p, x_{n}\right)+\sum_{i=1}^{\infty} \alpha_{n, i} \phi\left(p, S_{i}^{n} y_{n}\right)-\alpha_{n, 0} \alpha_{n, i} g\left\|J x_{n}-J S_{i}^{n} y_{n}\right\| \\
& \leq \alpha_{n, 0} \phi\left(p, x_{n}\right)+\zeta_{n} \sum_{i=1}^{\infty} \alpha_{n, i} \phi\left(p, y_{n}\right)-\alpha_{n, 0} \alpha_{n, i} g\left\|J x_{n}-J S_{i}^{n} y_{n}\right\| \\
& \leq \alpha_{n, 0} \phi\left(p, x_{n}\right)+\zeta_{n} \sum_{i=1}^{\infty} \alpha_{n, i}\left(\phi\left(p, x_{n}\right)+\xi_{n}\right)-\alpha_{n, 0} \alpha_{n, i} g\left\|J x_{n}-J S_{i}^{n} y_{n}\right\| \\
& \leq \alpha_{n, 0} \phi\left(p, x_{n}\right)+\zeta_{n} \sum_{i=1}^{\infty} \alpha_{n, i} \phi\left(p, x_{n}\right)+\xi_{n} \zeta_{n} \sum_{i=1}^{\infty} \alpha_{n, i}-\alpha_{n, 0} \alpha_{n, i} g\left\|J x_{n}-J S_{i}^{n} y_{n}\right\| \\
& \leq \zeta_{n} \phi\left(p, x_{n}\right)+\xi_{n} \zeta_{n} \sum_{i=1}^{\infty} \alpha_{n, i}-\alpha_{n, 0} \alpha_{n, i} g\left\|J x_{n}-J S_{i}^{n} y_{n}\right\| \\
& \leq \phi\left(p, x_{n}\right)+\sup _{p \in F}\left(\zeta_{n}-1\right) \phi\left(p, x_{n}\right)+\xi_{n} \zeta_{n} \sum_{i=1}^{\infty} \alpha_{n, i}-\alpha_{n, 0} \alpha_{n, i} g\left\|J x_{n}-J S_{i}^{n} y_{n}\right\| \\
& \leq \phi\left(p, x_{n}\right)+\delta_{n}+\xi_{n} \zeta_{n}-\alpha_{n, 0} \alpha_{n, i} g\left\|J x_{n}-J S_{i}^{n} y_{n}\right\| \\
& \leq \phi\left(p, x_{n}\right)+\theta_{n}
\end{aligned}
$$

where $\delta_{n}=\sup _{p \in \mathcal{F}}\left(\zeta_{n}-1\right) \phi\left(p, x_{n}\right), \theta_{n}=\delta_{n}+\xi_{n} \zeta_{n}$. By assumptions on $\left\{k_{n}\right\}$ and $\left\{\zeta_{n}\right\}$, we have

$$
\begin{aligned}
\xi_{n} & =\sup _{p \in \mathscr{F}}\left(k_{n}-1\right) \phi\left(p, x_{n}\right) \\
& \leq \sup _{p \in \mathscr{T}}\left(k_{n}-1\right)(\|p\|+M)^{2} \longrightarrow 0 \quad \text { as } n \longrightarrow \infty \\
\delta_{n} & =\sup _{p \in \mathscr{F}}\left(\zeta_{n}-1\right) \phi\left(p, x_{n}\right) \\
& \leq \sup _{p \in \mathscr{T}}\left(\zeta_{n}-1\right)(\|p\|+M)^{2} \longrightarrow 0 \quad \text { as } n \longrightarrow \infty
\end{aligned}
$$

where $M=\sup _{n \geq 0}\left\|x_{n}\right\|$. defined.

So, we have $p \in C_{n+1}$. This implies that $\mathcal{F} \in C_{n}$, for all $n \geq 0$ and also $\left\{x_{n}\right\}$ is well From Lemma 2.2 and $x_{n}=\prod_{C_{n}} x_{0}$, we have

$$
\begin{aligned}
& \left\langle x_{n}-z, J x_{0}-J x_{n}\right\rangle \geq 0, \quad \forall z \in C_{n}, \\
& \left\langle x_{n}-p, J x_{0}-J x_{n}\right\rangle \geq 0, \quad \forall p \in C_{n} .
\end{aligned}
$$

From Lemma 2.3, one has

$$
\phi\left(x_{n}, x_{0}\right)=\phi\left(\Pi_{C_{n}} x_{0}, x_{0}\right) \leq \phi\left(p, x_{0}\right)-\phi\left(p, x_{n}\right) \leq \phi\left(p, x_{0}\right)
$$


for all $p \in \mathcal{F} \subset C_{n}$ and $n \geq 1$. Then, the sequence $\left\{\phi\left(x_{n}, x_{0}\right)\right\}$ is also bounded. Thus $\left\{x_{n}\right\}$ is bounded. Since $x_{n}=\Pi_{C_{n}} x_{0}$ and $x_{n+1}=\Pi_{C_{n+1}} x_{0} \in C_{n+1} \subset C_{n}$, we have

$$
\phi\left(x_{n}, x_{0}\right) \leq \phi\left(x_{n+1}, x_{0}\right), \quad \forall n \in \mathbb{N} .
$$

Therefore, $\left\{\phi\left(x_{n}, x_{0}\right)\right\}$ is nondecreasing. Hence, the limit of $\left\{\phi\left(x_{n}, x_{0}\right)\right\}$ exists. By the construction of $C_{n}$, one has that $C_{m} \subset C_{n}$ and $x_{m}=\Pi_{C_{m}} x_{0} \in C_{n}$ for any positive integer $m \geq n$. It follows that

$$
\begin{aligned}
\phi\left(x_{m}, x_{n}\right) & =\phi\left(x_{m}, \Pi_{C_{n}} x_{0}\right) \\
& \leq \phi\left(x_{m}, x_{0}\right)-\phi\left(\Pi_{C_{n}} x_{0}, x_{0}\right) \\
& =\phi\left(x_{m}, x_{0}\right)-\phi\left(x_{n}, x_{0}\right) .
\end{aligned}
$$

Letting $m, n \rightarrow 0$ in (3.12), we get $\phi\left(x_{m}, x_{n}\right) \rightarrow 0$. It follows from Lemma 2.1, that $\| x_{m}-$ $x_{n} \| \rightarrow 0$ as $m, n \rightarrow \infty$. That is, $\left\{x_{n}\right\}$ is a Cauchy sequence.

Since $\left\{x_{n}\right\}$ is bounded and $E$ is reflexive, there exists a subsequence $\left\{x_{n_{i}}\right\} \subset\left\{x_{n}\right\}$ such that $x_{n_{i}} \rightarrow u$. Since $C_{n}$ is closed and convex and $C_{n+1} \subset C_{n}$, this implies that $C_{n}$ is weakly closed and $u \in C_{n}$ for each $n \geq 0$. since $x_{n}=\prod_{C_{n}} x_{0}$, we have

$$
\phi\left(x_{n_{i}}, x_{0}\right) \leq \phi\left(u, x_{0}\right), \quad \forall n_{i} \geq 0
$$

Since

$$
\begin{aligned}
\liminf _{n_{i} \rightarrow \infty} \phi\left(x_{n_{i}}, x_{0}\right) & =\liminf _{n_{i} \rightarrow \infty}\left\{\left\|x_{n_{i}}\right\|^{2}-2\left\langle x_{n_{i}}, J x_{0}\right\rangle+\left\|x_{0}\right\|^{2}\right\} \\
& \leq\|u\|^{2}-2\left\langle u, J x_{0}\right\rangle+\left\|x_{0}\right\|^{2} \\
& =\phi\left(u, x_{0}\right) .
\end{aligned}
$$

We have

$$
\phi\left(u, x_{0}\right) \leq \liminf _{n_{i} \rightarrow \infty} \phi\left(x_{n_{i}}, x_{0}\right) \leq \limsup _{n_{i} \rightarrow \infty} \phi\left(x_{n_{i}}, x_{0}\right) \leq \phi\left(u, x_{0}\right)
$$

This implies that $\lim _{n_{i} \rightarrow \infty} \phi\left(x_{n_{i}}, x_{0}\right)=\phi\left(u, x_{0}\right)$. That is, $\left\|x_{n_{i}}\right\| \rightarrow\|u\|$. Since $x_{n_{i}} \rightarrow u$, by the Kadec-klee property of $E$, we obtain that

$$
\lim _{n \rightarrow \infty} x_{n_{i}}=u
$$

If there exists some subsequence $\left\{x_{n_{j}}\right\} \subset\left\{x_{n}\right\}$ such that $x_{n_{j}} \rightarrow q$, then we have

$$
\begin{aligned}
\phi(u, q) & =\lim _{n_{i} \rightarrow \infty, n_{j} \rightarrow \infty} \phi\left(x_{n_{i}}, x_{n_{j}}\right) \leq \lim _{n_{i} \rightarrow \infty, n_{j} \rightarrow \infty}\left(\phi\left(x_{n_{i}}, x_{0}\right)-\phi\left(\Pi_{C_{n_{j}}} x_{0}, x_{0}\right)\right) \\
& =\lim _{n_{i} \rightarrow \infty, n_{j} \rightarrow \infty}\left(\phi\left(x_{n_{i}}, x_{0}\right)-\phi\left(x_{n_{j}} x_{0}, x_{0}\right)\right)=0 .
\end{aligned}
$$


Therefore, we have $u=q$. This implies that

$$
\lim _{n \rightarrow \infty} x_{n}=u
$$

Since

$$
\begin{aligned}
\phi\left(x_{n+1}, x_{n}\right) & =\phi\left(x_{n+1}, \Pi_{C_{n}} x_{0}\right) \leq \phi\left(x_{n+1}, x_{0}\right)-\phi\left(\Pi_{C_{n}} x_{0}, x_{0}\right) \\
& =\phi\left(x_{n+1}, x_{0}\right)-\phi\left(x_{n}, x_{0}\right)
\end{aligned}
$$

for all $n \in \mathbb{N}$, we also have

$$
\lim _{n \rightarrow \infty} \phi\left(x_{n+1}, x_{n}\right)=0
$$

Since $x_{n+1}=\Pi_{C_{n+1}} x_{0} \in C_{n+1}$ and by the definition of $C_{n+1}$, for $i=1,2, \ldots, N$, we have

$$
\phi\left(x_{n+1}, u_{n}^{i}\right) \leq \phi\left(x_{n+1}, x_{n}\right)+\theta_{n}
$$

Noticing that $\lim _{n \rightarrow \infty} \phi\left(x_{n+1}, x_{n}\right)=0$, we obtain

$$
\lim _{n \rightarrow \infty} \phi\left(x_{n+1}, u_{n}^{i}\right)=0, \quad \text { for } i=1,2, \ldots, N
$$

It then yields that $\lim _{n \rightarrow \infty}\left(\left\|x_{n+1}\right\|-\left\|u_{n}^{i}\right\|\right)=0$, for all $i=1,2, \ldots, N$. Since $\lim _{n \rightarrow \infty}\left\|x_{n+1}\right\|=\|u\|$, we have

$$
\lim _{n \rightarrow \infty}\left\|u_{n}^{i}\right\|=\|u\|, \quad \forall i=1,2, \ldots, N
$$

Hence,

$$
\lim _{n \rightarrow \infty}\left\|J u_{n}^{i}\right\|=\|J u\|, \quad \forall i=1,2, \ldots, N
$$

From Lemma 2.1 and (3.22), we have

$$
\lim _{n \rightarrow \infty}\left\|x_{n+1}-x_{n}\right\|=\lim _{n \rightarrow \infty}\left\|x_{n+1}-u_{n}^{i}\right\|=0, \quad \forall i=1,2, \ldots, N
$$

By the triangle inequality, we get

$$
\lim _{n \rightarrow \infty}\left\|x_{n}-u_{n}^{i}\right\|=0, \quad \forall i=1,2, \ldots, N
$$

Since $J$ is uniformly norm-to-norm continuous on bounded sets, we note that

$$
\lim _{n \rightarrow \infty}\left\|J x_{n}-J u_{n}^{i}\right\|=\lim _{n \rightarrow \infty}\left\|J x_{n+1}-J u_{n}^{i}\right\|=0, \quad \forall i=1,2, \ldots, N .
$$


Now, we prove that $u \in\left(\cap_{i=1}^{\infty} F\left(T_{i}\right)\right) \cap\left(\cap_{i=1}^{\infty} F\left(S_{i}\right)\right)$. From the construction of $C_{n}$, we obtain that

$$
\phi\left(x_{n+1}, y_{n}\right) \leq \phi\left(x_{n+1}, x_{n}\right)+\xi_{n} .
$$

From (3.7) and (3.20), we have

$$
\lim _{n \rightarrow \infty} \phi\left(x_{n+1}, y_{n}\right)=0
$$

By Lemma 2.1, we also have

$$
\lim _{n \rightarrow \infty}\left\|x_{n+1}-y_{n}\right\|=0
$$

Since $J$ is uniformly norm-to-norm continuous on bounded sets, we note that

$$
\lim _{n \rightarrow \infty}\left\|J x_{n+1}-J y_{n}\right\|=0
$$

From (2.4) and (3.29), we have $\left(\left\|x_{n+1}\right\|-\left\|y_{n}\right\|\right)^{2} \rightarrow 0$. Since $\left\|x_{n+1}\right\| \rightarrow\|u\|$, it yields that

$$
\left\|y_{n}\right\| \longrightarrow\|u\| \text { as } n \longrightarrow \infty
$$

Since $J$ is uniformly norm-to-norm continuous on bounded sets, it follows that

$$
\left\|J y_{n}\right\| \longrightarrow\|J u\| \quad \text { as } n \longrightarrow \infty
$$

This implies that $\left\{J y_{n}\right\}$ is bounded in $E^{*}$. Since $E$ is reflexive, there exists a subsequence $\left\{J y_{n_{i}}\right\} \subset\left\{J y_{n}\right\}$ such that $J y_{n_{i}} \rightarrow r \in E^{*}$. Since $E$ is reflexive, we see that $J(E)=E^{*}$. Hence, there exists $x \in E$ such that $J x=r$. We note that

$$
\begin{aligned}
\phi\left(x_{n_{i}+1}, y_{n_{i}}\right) & =\left\|x_{n_{i}+1}\right\|^{2}-2\left\langle x_{n_{i}+1}, J y_{n_{i}}\right\rangle+\left\|y_{n_{i}}\right\|^{2} \\
& =\left\|x_{n_{i}+1}\right\|^{2}-2\left\langle x_{n_{i}+1}, J y_{n_{i}}\right\rangle+\left\|J y_{n_{i}}\right\|^{2} .
\end{aligned}
$$

Taking the limit interior of both side and in view of weak lower semicontinuity of norm $\|\cdot\|$, we have

$$
\begin{aligned}
0 & \geq\|u\|^{2}-2\langle u, r\rangle+\|r\|^{2} \\
& =\|u\|^{2}-2\langle u, J x\rangle+\|J x\|^{2} \\
& =\|u\|^{2}-2\langle u, J x\rangle+\|x\|^{2}=\phi(u, x),
\end{aligned}
$$

that is, $u=x$. This implies that $r=J u$ and so $J y_{n} \rightarrow J p$. It follows from $\lim _{n \rightarrow \infty}\left\|J y_{n}\right\|=$ $\|J u\|$, as $n \rightarrow \infty$ and the Kadec-Klee property of $E^{*}$ that $J y_{n_{i}} \rightarrow J u$ as $n \rightarrow \infty$. Note 
that $J^{-1}: E^{*} \rightarrow E$ is hemicontinuous, it yields that $y_{n_{i}} \rightarrow u$. It follows from $\lim _{n \rightarrow \infty}\left\|u_{n}\right\|=$ $\|u\|$, as $n \rightarrow \infty$ and the Kadec-Klee property of $E$ that $\lim _{n_{i} \rightarrow \infty} y_{n_{i}}=u$.

By similar, we can prove that

$$
\lim _{n \rightarrow \infty} y_{n}=u
$$

By (3.20) and (3.30), we obtain

$$
\lim _{n \rightarrow \infty}\left\|x_{n}-y_{n}\right\|=0
$$

Since $J$ is uniformly norm-to-norm continuous on bounded sets, we note that

$$
\lim _{n \rightarrow \infty}\left\|J x_{n}-J y_{n}\right\|=0
$$

So, from (3.27) and (3.31), by the triangle inequality, we get

$$
\lim _{n \rightarrow \infty}\left\|J y_{n}-J u_{n}^{i}\right\|=0, \quad \text { for } i=1,2, \ldots, N
$$

Since $J^{-1}$ is uniformly norm-to-norm continuous on bounded sets, we note that

$$
\lim _{n \rightarrow \infty}\left\|y_{n}-u_{n}^{i}\right\|=0, \quad \text { for } i=1,2, \ldots, N
$$

Since

$$
\begin{aligned}
\phi\left(p, x_{n}\right)-\phi\left(p, y_{n}\right) & =\left\|x_{n}\right\|^{2}-\left\|y_{n}\right\|^{2}-2\left\langle p, J x_{n}-J y_{n}\right\rangle \\
& \leq\left\|x_{n}\right\|^{2}-\left\|y_{n}\right\|^{2}+2\|p\|\left\|J x_{n}-J y_{n}\right\| \\
& \leq\left\|x_{n}-y_{n}\right\|\left(\left\|x_{n}\right\|+\left\|y_{n}\right\|\right)+2\|p\|\left\|J x_{n}-J y_{n}\right\|
\end{aligned}
$$

From (3.37) and (3.38), we obtain

$$
\phi\left(p, x_{n}\right)-\phi\left(p, y_{n}\right) \longrightarrow 0, \quad n \longrightarrow \infty
$$

On the other hand, we observe that, for $i=1,2, \ldots, N$.

$$
\begin{aligned}
\phi\left(p, x_{n}\right)-\phi\left(p, u_{n}^{i}\right) & =\left\|x_{n}\right\|^{2}-\left\|u_{n}^{i}\right\|^{2}-2\left\langle p, J x_{n}-J u_{n}^{i}\right\rangle \\
& \leq\left\|x_{n}\right\|^{2}-\left\|u_{n}^{i}\right\|^{2}+2\|p\|\left\|J x_{n}-J u_{n}^{i}\right\| \\
& \leq\left\|x_{n}-u_{n}^{i}\right\|\left(\left\|x_{n}\right\|+\left\|u_{n}^{i}\right\|\right)+2\|p\|\left\|J x_{n}-J u_{n}^{i}\right\| .
\end{aligned}
$$


From (3.22) and (3.27), we have

$$
\phi\left(p, x_{n}\right)-\phi\left(p, u_{n}^{i}\right) \longrightarrow 0, \quad n \longrightarrow \infty, \forall i=1,2, \ldots, N
$$

For any $p \in \cap_{i=1}^{N} \Omega_{i} \cap\left(\cap_{i=1}^{\infty} \mathrm{F}\left(T_{i}\right)\right) \cap\left(\cap_{i=1}^{\infty} F\left(S_{i}\right)\right)$, it follows from (3.5) that

$$
\beta_{n, 0} \beta_{n, i} g\left(\left\|J x_{n}-J T_{i}^{n} x_{n}\right\|\right) \leq \phi\left(p, x_{n}\right)+\xi_{n}-\phi\left(p, y_{n}\right)
$$

From condition, $\lim \inf _{n \rightarrow \infty} \beta_{n, 0} \beta_{n, i}>0$, property of $g$, (3.7), and (3.42), we have that

$$
\left\|J x_{n}-J T_{i}^{n} x_{n}\right\| \longrightarrow 0, \quad n \longrightarrow \infty, \forall i=1,2, \ldots, N
$$

Since $x_{n} \rightarrow u$ and $J$ is uniformly norm-to-norm continuous. It yields $J x_{n} \rightarrow J p$. Hence from (3.46), we have

$$
\left\|x_{n}-T_{i}^{n} x_{n}\right\| \longrightarrow 0, \quad n \longrightarrow \infty, \forall i=1,2, \ldots, N
$$

Since $x_{n} \rightarrow u$, this implies that $\lim _{n \rightarrow \infty} J T_{i}^{n} x_{n} \rightarrow J u$ as $n \rightarrow \infty$. Since $J^{-1}: E^{*} \rightarrow E$ is hemicontinuous, it follows that

$$
T_{i}^{n} x_{n} \rightarrow u, \quad \text { for each } i \geq 1 \text {. }
$$

On the other hand, for each $i \geq 1$, we have

$$
\begin{aligned}
\left\|T_{i}^{n} x_{n}\right\|-\|u\| & =\left|\left\|T_{i}^{n} x_{n}\right\|-\|u\|\right| \\
& \leq\left\|T_{i}^{n} x_{n}-u\right\| \longrightarrow 0, \quad n \longrightarrow \infty
\end{aligned}
$$

from this, together with (3.48) and the Kadec-Klee property of $E$, we obtain

$$
T_{i}^{n} x_{n} \longrightarrow u, \quad \text { for each } i \geq 1 \text {. }
$$

On the other hand, by the assumption that $T_{i}$ is uniformly $L_{i}$-Lipschitz continuous, we have

$$
\begin{aligned}
\left\|T_{i}^{n+1} x_{n}-T_{i}^{n} x_{n}\right\| \leq & \left\|T_{i}^{n+1} x_{n}-T_{i}^{n+1} x_{n+1}\right\|+\left\|T_{i}^{n+1} x_{n+1}-x_{n+1}\right\| \\
& +\left\|x_{n+1}-x_{n}\right\|+\left\|x_{n}-T_{i}^{n} x_{n}\right\| \\
\leq & \left(L_{i}+1\right)\left\|x_{n+1}-x_{n}\right\|+\left\|T_{i}^{n+1} x_{n+1}-x_{n+1}\right\| \\
& +\left\|x_{n}-T_{i}^{n} x_{n}\right\| .
\end{aligned}
$$


By (3.18) and (3.50), we obtain

$$
\lim _{n \rightarrow \infty}\left\|T_{i}^{n+1} x_{n}-T_{i}^{n} x_{n}\right\|=0, \quad \forall i \geq 1,
$$

and $\lim _{n \rightarrow \infty} T_{i}^{n+1} x_{n}=u$, that is, $T_{i} T^{n} x_{n} \rightarrow u$, for all $i \geq 1$. By the closeness of $T_{i}$, we have $T_{i} u=\mathrm{u}$, for all $i \geq 1$. This implies that $u \in \cap_{i=1}^{\infty} F\left(T_{i}\right)$.

By the similar way, we can prove that for each $i \geq 1$

$$
\left\|J x_{n}-J S_{i}^{n} y_{n}\right\| \longrightarrow 0, \quad n \longrightarrow \infty
$$

Since $x_{n} \rightarrow u$ and $J$ is uniformly norm-to-norm continuous. it yields $J x_{n} \rightarrow J p$. Hence from (3.53), we have

$$
\left\|x_{n}-S_{i}^{n} y_{n}\right\| \longrightarrow 0, \quad n \longrightarrow \infty
$$

Since $x_{n} \rightarrow u$, this implies that $\lim _{n \rightarrow \infty} J S_{i}^{n} y_{n} \rightarrow J u$ as $n \rightarrow \infty$. Since $J^{-1}: E^{*} \rightarrow E$ is hemicontinuous, it follows that

$$
S_{i}^{n} y_{n} \rightarrow u, \quad \text { for each } i \geq 1 \text {. }
$$

On the other hand, for each $i \geq 1$, we have

$$
\begin{aligned}
\left\|S_{i}^{n} y_{n}\right\|-\|u\| & =\left|\left\|S_{i}^{n} y_{n}\right\|-\|u\|\right| \\
& \leq\left\|S_{i}^{n} y_{n}-u\right\| \longrightarrow 0, \quad n \longrightarrow \infty
\end{aligned}
$$

From this, together with (3.54) and the Kadec-Klee property of E, we obtain

$$
S_{i}^{n} y_{n} \longrightarrow u, \quad \text { for each } i \geq 1
$$

On the other hand, by the assumption that $S_{i}$ is uniformly $\mu_{i}$-Lipschitz continuous, we have

$$
\begin{aligned}
\left\|S_{i}^{n+1} y_{n}-S_{i}^{n} y_{n}\right\| \leq & \left\|S_{i}^{n+1} y_{n}-S_{i}^{n+1} y_{n+1}\right\|+\left\|S_{i}^{n+1} y_{n+1}-y_{n+1}\right\| \\
& +\left\|y_{n+1}-y_{n}\right\|+\left\|y_{n}-S_{i}^{n} y_{n}\right\| \\
\leq & \left(\mu_{i}+1\right)\left\|y_{n+1}-y_{n}\right\|+\left\|S_{i}^{n+1} y_{n+1}-y_{n+1}\right\| \\
& +\left\|y_{n}-S_{i}^{n} y_{n}\right\| .
\end{aligned}
$$


By (3.36) and (3.57), we obtain

$$
\lim _{n \rightarrow \infty}\left\|S_{i}^{n+1} y_{n}-S_{i}^{n} y_{n}\right\|=0
$$

and $\lim _{n \rightarrow \infty} S_{i}^{n+1} y_{n}=u$, that is, $S_{i} T^{n} y_{n} \rightarrow u$. By the closeness of $S_{i}$, we have $S_{i} u=u$, for all $i \geq$ 1. This implies that $u \in \cap_{i=1}^{\infty} F\left(S_{i}\right)$. Hence $u \in\left(\cap_{i=1}^{\infty} F\left(T_{i}\right)\right) \cap\left(\cap_{i=1}^{\infty} F\left(S_{i}\right)\right)$.

Next, we prove that $u \in \cap_{i=1}^{N} \Omega_{i}$. For any $p \in \mathcal{F}$, for each $i=1,2, \ldots, N$, we have

$$
\begin{aligned}
\phi\left(u_{n}^{i}, z_{n}\right) & =\phi\left(\Theta_{n}^{i} z_{n}, z_{n}\right) \\
& \leq \phi\left(p, z_{n}\right)-\phi\left(p, \Theta_{n}^{i} z_{n}\right) \\
& =\phi\left(p, z_{n}\right)-\phi\left(p, u_{n}^{i}\right) \\
& \leq \phi\left(p, x_{n}\right)+\theta_{n}-\phi\left(p, u_{n}^{i}\right) \rightarrow 0, \quad \text { as } n \rightarrow \infty
\end{aligned}
$$

It then yields that $\lim _{n \rightarrow \infty}\left(\left\|u_{n}^{i}\right\|-\left\|z_{n}\right\|\right)=0$. Since $\lim _{n \rightarrow \infty}\left\|u_{n}^{i}\right\|=\|u\|$, for all $i \geq 1$, we have

$$
\lim _{n \rightarrow \infty}\left\|z_{n}\right\|=\|u\|
$$

Hence,

$$
\lim _{n \rightarrow \infty}\left\|J z_{n}\right\|=\|J u\|
$$

This together with $\lim _{n \rightarrow \infty}\left\|u_{n}^{i}\right\|=\|u\|$ show that for each $i=1,2, \ldots, N$,

$$
\lim _{n \rightarrow \infty}\left\|u_{n}^{i}-u_{n}^{i-1}\right\|=\lim _{n \rightarrow \infty}\left\|J u_{n}^{i}-J u_{n}^{i-1}\right\|=0,
$$

where $u_{n}^{0}=z_{n}$. On the other hand, we have

$$
u_{n}^{i}=K_{f_{i}, r_{i}} u_{n}^{i-1}, \quad \text { for each } i=2,3, \ldots, N,
$$

and $u_{n}^{i}$ is a solution of the following variational equation

$$
f_{i}\left(u_{n}^{i}, y\right)+\left\langle A_{i} u_{n}^{i}, y-u_{n}^{i}\right\rangle+\psi_{i}(y)-\psi_{i}\left(u_{n}^{i}\right)+\frac{1}{r_{i}}\left\langle y-u_{n}^{i} J u_{n}^{i}-J u_{n}^{i-1}\right\rangle \geq 0, \quad \forall y \in C .
$$

By condition (A2), we note that

$$
\begin{gathered}
\left\langle A_{i} u_{n}^{i}, y-u_{n}^{i}\right\rangle+\psi_{i}(y)-\psi_{i}\left(u_{n}^{i}\right)+\frac{1}{r_{i}}\left\langle y-u_{n}^{i} J u_{n}^{i}-J u_{n}^{i-1}\right\rangle \\
\geq-f_{i}\left(u_{n}^{i}, y\right) \geq f_{i}\left(y, u_{n}^{i}\right), \quad \forall y \in C .
\end{gathered}
$$


By (A4), (3.63), and $u_{n}^{i} \rightarrow u$ for each $i=2,3, \ldots, N$, we have

$$
\left\langle A_{i} u, y-u\right\rangle+\psi_{i}(y)-\psi_{i}(u) \geq f_{i}(y, u), \quad \forall y \in C .
$$

For $0<t<1$ and $y \in C$, define $y_{t}=t y+(1-t) u$. Noticing that $y, u \in C$, we obtain $y_{t} \in C$, which yields that

$$
\left\langle A_{i} u, y_{t}-u\right\rangle+\psi_{i}\left(y_{t}\right)-\psi_{i}(u) \geq f_{i}\left(y_{t}, u\right)
$$

In view of the convexity of $\phi$ it yields

$$
t\left\langle A_{i} u, y-u\right\rangle+t\left(\psi_{i}(y)-\psi_{i}(u)\right) \geq f_{i}\left(y_{t}, u\right)
$$

It follows from (A1) and (A4) that

$$
\begin{aligned}
0 & =f_{i}\left(y_{t}, y_{t}\right) \leq t f_{i}\left(y_{t}, y\right)+(1-t) f_{i}\left(y_{t}, u\right) \\
& \leq t f_{i}\left(y_{t}, y\right)+(1-t) t\left[\left\langle A_{i} u, y-u\right\rangle+\left(\psi_{i}(y)-\psi_{i}(u)\right)\right]
\end{aligned}
$$

Let $t \rightarrow 0$, from (A3), we obtain the following:

$$
f_{\mathrm{i}}(u, y)+\left\langle A_{i} u, y-u\right\rangle+\psi_{i}(y)-\psi_{i}(u) \geq 0, \quad \forall y \in C, i=1,2, \ldots, N
$$

This implies that $u$ is a solution of the system of generalized mixed equilibrium problem (3.2), that is, $u \in \cap_{i=1}^{N} \Omega_{i}$. Hence, $u \in \mathcal{F}:=\left(\cap_{i=1}^{N} \Omega_{i}\right) \cap\left(\cap_{i=1}^{\infty} F\left(T_{i}\right)\right) \cap\left(\cap_{i=1}^{\infty} F\left(S_{i}\right)\right)$.

Finally, we show that $x_{n} \rightarrow u=\Pi_{F} x_{0}$. Indeed from $w \in F \subset C_{n}$ and $x_{n}=\Pi_{C_{n}} x_{0}$, we have the following:

$$
\phi\left(x_{n}, x_{0}\right) \leq \phi\left(w, x_{0}\right), \quad \forall n \geq 0 .
$$

This implies that

$$
\phi\left(u, x_{0}\right)=\lim _{n \rightarrow \infty} \phi\left(x_{n}, x_{0}\right) \leq \phi\left(w, x_{0}\right) .
$$

From the definition of $\Pi_{F} x_{0}$ and (3.73), we see that $u=w$. This completes the proof.

Since every asymptotically relatively nonexpansive mappings is quasi- $\phi$-nonexpansive mappings, hence we obtain the following corollary.

Corollary 3.2. Let $E$ be a uniformly convex and uniformly smooth Banach space, let $C$ be a nonempty, closed, and convex subset of $E$. Let $A_{i}: C \rightarrow E^{*}$ be a continuous and monotone mapping, $\psi_{i}: C \rightarrow \mathbb{R}$ be a lower semi-continuous and convex function, $f_{i}$ be a bifunction from $C \times C$ to $\mathbb{R}$ satisfying (A1)-(A4), $K_{f_{i}, r_{i}}$ is the mapping defined by (2.10) where $r_{i} \geq r>0$, and let $\left\{T_{i}\right\}_{i=1}^{\infty},\left\{S_{i}\right\}_{i=1}^{\infty}$ be countable families of closed and quasi- $\phi$-nonexpansive mapping such that 
$\mathcal{F}:=\left(\cap_{i=1}^{N} \Omega_{i}\right) \cap\left(\cap_{i=1}^{\infty} F\left(T_{i}\right)\right) \cap\left(\cap_{i=1}^{\infty} F\left(S_{i}\right)\right) \neq \emptyset$. Let $\left\{x_{n}\right\}$ be a sequence generated by $x_{0} \in C$ and $C_{0}=C$, such that

$$
\begin{gathered}
y_{n}=J^{-1}\left(\beta_{n, 0} J\left(x_{n}\right)+\sum_{i=1}^{\infty} \beta_{n, i} J\left(T_{i} x_{n}\right)\right), \\
z_{n}=J^{-1}\left(\alpha_{n, 0} J\left(x_{n}\right)+\sum_{i=1}^{\infty} \alpha_{n, i} J\left(S_{i} y_{n}\right)\right), \\
C_{n+1}^{(i)}=\left\{K_{f_{i}, r_{i}} K_{f_{i-1}, r_{i-1}} \cdots K_{f_{1}, r_{1}}\left(z_{n}\right), \quad i=1,2, \ldots, N,\right. \\
\left.z \in C_{n}: \max _{i=1,2, \ldots, N} \phi\left(z, u_{n}^{(i)}\right) \leq \phi\left(z, x_{n}\right), \phi\left(z, y_{n}\right) \leq \phi\left(z, x_{n}\right)\right\}, \\
x_{n+1}=\prod_{C_{n+1}} x_{0}, \quad \forall n \geq 0,
\end{gathered}
$$

where $\Pi_{C}$ is the generalized projection from $E$ onto $C, J$ is the duality mapping on $E$. The coefficient sequences $\left\{\alpha_{n, i}\right\}$ and $\left\{\beta_{n, i}\right\} \subset[0,1]$, satisfying:

(i) $\sum_{i=0}^{\infty} \alpha_{n, i}=1$;

(ii) $\sum_{i=0}^{\infty} \beta_{n, i}=1$;

(iii) $\liminf _{n \rightarrow \infty} \alpha_{n, 0} \alpha_{n, i}>0$, for all $i \geq 1$;

(iv) $\liminf _{n \rightarrow \infty} \beta_{n, 0} \beta_{n, i}>0$, for all $i \geq 1$.

$\Omega_{i}, i=1,2, \ldots, N$ is the set of solutions to the following generalized mixed equilibrium problem:

$$
f_{i}(z, y)+\left\langle A_{i} z, y-z\right\rangle+\psi_{i}(y)-\psi_{i}(z) \geq 0, \quad \forall y \in C, i=1,2, \ldots, N
$$

Then the sequence $\left\{x_{n}\right\}$ converges strongly to $\Pi_{\mp} x_{0}$. corollary.

If $A_{i}=A, \psi_{i}=\psi$, and $f_{i}=f$ for all $i \geq 1$ in Theorem 3.1, we obtain the following

Corollary 3.3. Let $E$ be a uniformly smooth and uniformly convex Banach space, let $C$ be a nonempty, closed, and convex subset of $E$. Let $A: C \rightarrow E^{*}$ be a continuous and monotone mapping, $\psi: C \rightarrow \mathbb{R}$ be a lower semicontinuous and convex function, $f$ be a bifunction from $C \times C$ to $\mathbb{R}$ satisfying $(A 1)-(A 4), K_{f, r}$ be the mapping define by (2.10) where $r>0$, and let $\left\{T_{i}\right\}_{i=1}^{\infty}$, $\left\{S_{i}\right\}_{i=1}^{\infty}$ be countable families of closed and uniformly $L_{i}, \mu_{i}$-Lipschitz continuous, and asymptotically relatively nonexpansive mappings with sequence $\left\{k_{n}\right\},\left\{\zeta_{n}\right\} \subset[1, \infty) ; k_{n} \rightarrow 1, \zeta_{n} \rightarrow 1$ such that 
$\mathcal{F}:=\Omega \cap\left(\cap_{i=1}^{\infty} F\left(T_{i}\right)\right) \cap\left(\cap_{i=1}^{\infty} F\left(S_{i}\right)\right) \neq \emptyset$. Let $\left\{x_{n}\right\}$ be a sequence generated by $x_{0} \in C$ and $C_{0}=C$, such that

$$
\begin{gathered}
y_{n}=J^{-1}\left(\beta_{n, 0} J\left(x_{n}\right)+\sum_{i=1}^{\infty} \beta_{n, i} J\left(T_{i}^{n} x_{n}\right)\right), \\
z_{n}=J^{-1}\left(\alpha_{n, 0} J\left(x_{n}\right)+\sum_{i=1}^{\infty} \alpha_{n, i} J\left(S_{i}^{n} y_{n}\right)\right), \\
u_{n}=K_{f, r} z_{n} \\
C_{n+1}=\left\{z \in C_{n}: \max _{i=1,2, \ldots, N} \phi\left(z, u_{n}^{(i)}\right) \leq \phi\left(z, x_{n}\right)+\theta_{n}, \phi\left(z, y_{n}\right) \leq \phi\left(z, x_{n}\right)+\xi_{n}\right\}, \\
x_{n+1}=\prod_{C_{n+1}} x_{0}, \quad \forall n \geq 0,
\end{gathered}
$$

where $\xi_{n}=\sup _{p \in \mathcal{F}}\left(k_{n}-1\right) \phi\left(p, x_{n}\right), \theta_{n}=\delta_{n}+\xi_{n} \zeta_{n}$, and $\delta_{n}=\sup _{p \in \mathcal{F}}\left(\zeta_{n}-1\right) \phi\left(p, x_{n}\right)$. The coefficient sequences $\left\{\alpha_{n, i}\right\}$ and $\left\{\beta_{n, i}\right\} \subset[0,1]$, satisfying:

(i) $\sum_{i=0}^{\infty} \alpha_{n, i}=1$;

(ii) $\sum_{i=0}^{\infty} \beta_{n, i}=1$;

(iii) $\liminf _{n \rightarrow \infty} \alpha_{n, 0} \alpha_{n, i}>0$, for all $i \geq 1$;

(iv) $\lim \inf _{n \rightarrow \infty} \beta_{n, 0} \beta_{n, i}>0$, for all $i \geq 1$.

Then the sequence $\left\{x_{n}\right\}$ converges strongly to $\Pi_{\mp} x_{0}$.

If $i=1$ in Theorem 3.1, then we obtain the following corollary.

Corollary 3.4. Let E be a uniformly smooth and uniformly convex Banach space, let $C$ be a nonempty, closed, and convex subset of $E$. Let $A: C \rightarrow E^{*}$ be a continuous and monotone mapping, $\psi: C \rightarrow \mathbb{R}$ be a lower semicontinuous and convex function, $f$ be a bifunction from $C \times C$ to $\mathbb{R}$ satisfying $(A 1)-(A 4), K_{f, r}$ is the mapping define by (2.10) where $r>0$, and let $T, S$ are two closed and uniformly $L, \mu$-Lipschitz continuous and asymptotically relatively nonexpansive mappings with sequence $\left\{k_{n}\right\},\left\{\zeta_{n}\right\} \subset[1, \infty) ; k_{n} \rightarrow 1, \zeta_{n} \rightarrow 1$ such that $\mathcal{F}:=\Omega \cap F(T) \cap F(S) \neq \emptyset$. Let $\left\{x_{n}\right\}$ be a sequence generated by $x_{0} \in C$ and $C_{0}=C$, we have

$$
\begin{gathered}
y_{n}=J^{-1}\left(\beta_{n} J x_{n}+\left(1-\beta_{n}\right) J T^{n} x_{n}\right), \\
z_{n}=J^{-1}\left(\alpha_{n} J x_{n}+\left(1-\alpha_{n}\right) J S^{n} y_{n}\right), \\
u_{n}=K_{f, r} z_{n}, \\
C_{n+1}=\left\{z \in C_{n}: \phi\left(z, u_{n}\right) \leq \phi\left(z, x_{n}\right)+\theta_{n}, \phi\left(z, y_{n}\right) \leq \phi\left(z, x_{n}\right)+\xi_{n}\right\}, \\
x_{n+1}=\prod_{C_{n+1}} x_{0}, \quad \forall n \geq 0,
\end{gathered}
$$

where $\xi_{n}=\sup _{p \in \mathcal{F}}\left(k_{n}-1\right) \phi\left(p, x_{n}\right), \theta_{n}=\delta_{n}+\xi_{n} \zeta_{n}$, and $\delta_{n}=\sup _{p \in \mathcal{F}}\left(\zeta_{n}-1\right) \phi\left(p, x_{n}\right)$. The coefficient sequences $\left\{\alpha_{n}\right\}$ and $\left\{\beta_{n}\right\} \subset[0,1]$, satisfying 
(D1) $\liminf _{n \rightarrow \infty} \alpha_{n}\left(1-\alpha_{n}\right)>0$;

(D2) $\liminf _{n \rightarrow \infty} \beta_{n}\left(1-\beta_{n}\right)>0$.

Then the sequence $\left\{x_{n}\right\}$ converges strongly to $\Pi_{q} x_{0}$.

Remark 3.5. Theorem 3.1 and Corollary 3.3 improve and extend the corresponding results of Petrot et al. [24], Kumam and Wattanawitoon [25], and Chang et al. [26] in the following senses:

(i) for the mappings, we extend the mappings from nonexpansive mappings, hemirelatively nonexpansive mappings to two infinite family of closed asymptotically relatively nonexpansive mappings;

(ii) from a solution of the classical equilibrium problem to a system of generalized mixed equilibrium problems and the generalized mixed equilibrium problem with an infinite family of closed relatively nonexpansive mappings.

Remark 3.6. Corollary 3.4 improves and extends the corresponding results of Theorem 3.1 in Kumam and Wattanawitoon [25] and Corollary 3.3 in Saewan et al. [11] in the following senses:

(i) the mapping in [11] and [25]

(ii) the conditions (D1) and (D2) of the parameters $\left\{\alpha_{n}\right\}$ and $\left\{\beta_{n}\right\}$ are weaker and not complicated than the conditions (C1)-(C3) in [[25], Theorem 3.1] and [[11], Theorem 3.1] which are easy to compute.

\section{Acknowledgments}

This first author was supported by The Hands-On Research and Development, Rajamangala University of Technology Lanna (Grant no. UR2L003). Moreover, this work was supported by the Higher Education Research Promotion and National Research University Project of Thailand, Office of the Higher Education Commission (NRU-CSEC Grant no. 55000613).

\section{References}

[1] E. Blum and W. Oettli, "From optimization and variational inequalities to equilibrium problems," The Mathematics Student, vol. 63, no. 1-4, pp. 123-145, 1994.

[2] S. D. Flåm and A. S. Antipin, "Equilibrium programming using proximal-like algorithms," Mathematical Programming, vol. 78, no. 1, pp. 29-41, 1997.

[3] A. Moudafi and M. Théra, "Proximal and dynamical approaches to equilibrium problems," in IllPosed Variational Problems and Regularization Techniques, vol. 477 of Lecture Notes in Econom. and Math. Systems, pp. 187-201, Springer, Berlin, Germany, 1999.

[4] S. Takahashi and W. Takahashi, "Viscosity approximation methods for equilibrium problems and fixed point problems in Hilbert spaces," Journal of Mathematical Analysis and Applications, vol. 331, no. 1 , pp. 506-515, 2007.

[5] P. L. Combettes and S. A. Hirstoaga, "Equilibrium programming in Hilbert spaces," Journal of Nonlinear and Convex Analysis, vol. 6, no. 1, pp. 117-136, 2005.

[6] S. Saewan and P. Kumam, "Modified hybrid block iterative algorithm for convex feasibility problems and generalized equilibrium problems for uniformly quasi- $\varphi$-asymptotically nonexpansive mappings," Abstract and Applied Analysis, vol. 2010, Article ID 357120, 22 pages, 2010.

[7] S. Saewan and P. Kumam, "A hybrid iterative scheme for a maximal monotone operator and two countable families of relatively quasi-nonexpansive mappings for generalized mixed equilibrium and 
variational inequality problems," Abstract and Applied Analysis, vol. 2010, Article ID 123027, 31 pages, 2010.

[8] S. Saewan and P. Kumam, "The shrinking projection method for solving generalized equilibrium problems and common fixed points for asymptotically quasi- $\varphi$-nonexpansive mappings," Fixed Point Theory and Applications, vol. 2011, article 9, 2011.

[9] S. Saewan and P. Kumam, "Strong convergence theorems for countable families of uniformly quasi- $\varphi$ asymptotically nonexpansive mappings and a system of generalized mixed equilibrium problems," Abstract and Applied Analysis, vol. 2011, Article ID 701675, 27 pages, 2011.

[10] S. Saewan and P. Kumam, "A modified hybrid projection method for solving generalized mixed equilibrium problems and fixed point problems in Banach spaces," Computers $\mathcal{E}$ Mathematics with Applications, vol. 62, no. 4, pp. 1723-1735, 2011.

[11] S. Saewan, P. Kumam, and K. Wattanawitoon, "Convergence theorem based on a new hybrid projection method for finding a common solution of generalized equilibrium and variational inequality problems in Banach spaces," Abstract and Applied Analysis, vol. 2010, Article ID 734126, 25 pages, 2010.

[12] A. Tada and W. Takahashi, "Strong convergence theorem for an equilibrium problem and a nonexpansive mapping," in Nonlinear Analysis and Convex Analysis, pp. 609-617, Yokohama Publisher, Yokohama, Japan, 2006.

[13] A. Tada and W. Takahashi, "Weak and strong convergence theorems for a nonexpansive mapping and an equilibrium problem," Journal of Optimization Theory and Applications, vol. 133, no. 3, pp. 359-370, 2007.

[14] H. Zegeye and N. Shahzad, "Approximating common solution of variational inequality problems for two monotone mappings in Banach spaces," Optimization Letters, vol. 5, no. 4, pp. 691-704, 2011.

[15] S. S. Zhang, C. K. Chan, and H. W. Joseph Lee, "Modified block iterative method for solving convex feasibility problem, equilibrium problems and variational inequality problems," Acta Mathematica Sinica, vol. 28, no. 4, pp. 741-758, 2012.

[16] W. A. Kirk, "A fixed point theorem for mappings which do not increase distances," The American Mathematical Monthly, vol. 72, pp. 1004-1006, 1965.

[17] S. Reich, "A weak convergence theorem for the alternating method with Bregman distances," in Theory and Applications of Nonlinear Operators of Accretive and Monotone Type, vol. 178 of Lecture Notes in Pure and Applied Mathematics, pp. 313-318, Dekker, New York, NY, USA, 1996.

[18] W. Nilsrakoo and S. Saejung, "Strong convergence to common fixed points of countable relatively quasi-nonexpansive mappings," Fixed Point Theory and Applications, vol. 2008, Article ID 312454, 19 pages, 2008.

[19] Y. Su, D. Wang, and M. Shang, "Strong convergence of monotone hybrid algorithm for hemi-relatively nonexpansive mappings," Fixed Point Theory and Applications, vol. 2008, Article ID 284613, 8 pages, 2008.

[20] H. Zegeye and N. Shahzad, "Strong convergence theorems for monotone mappings and relatively weak nonexpansive mappings," Nonlinear Analysis: Theory, Methods E Applications, vol. 70, no. 7, pp. 2707-2716, 2009.

[21] D. Butnariu, S. Reich, and A. J. Zaslavski, "Asymptotic behavior of relatively nonexpansive operators in Banach spaces," Journal of Applied Analysis, vol. 7, no. 2, pp. 151-174, 2001.

[22] Y. Censor and S. Reich, "Iterations of paracontractions and firmly nonexpansive operators with applications to feasibility and optimization," Optimization, vol. 37, no. 4, pp. 323-339, 1996.

[23] Y. Su, H.-k. Xu, and X. Zhang, "Strong convergence theorems for two countable families of weak relatively nonexpansive mappings and applications," Nonlinear Analysis: Theory, Methods \& Applications, vol. 73, no. 12, pp. 3890-3906, 2010.

[24] N. Petrot, K. Wattanawitoon, and P. Kumam, "Strong convergence theorems of modified Ishikawa iterations for countable hemi-relatively nonexpansive mappings in a Banach space," Fixed Point Theory and Applications, vol. 2009, Article ID 483497, 25 pages, 2009.

[25] P. Kumam and K. Wattanawitoon, "Convergence theorems of a hybrid algorithm for equilibrium problems," Nonlinear Analysis: Hybrid Systems, vol. 3, no. 4, pp. 386-394, 2009.

[26] S.-s. Chang, J. K. Kim, and X. R. Wang, "Modified block iterative algorithm for solving convex feasibility problems in Banach spaces," Journal of Inequalities and Applications, vol. 2010, Article ID 869684, 14 pages, 2010.

[27] J. F. Tan and S. S. Chang, "A new hybrid algorithm for solving a system of generalized mixed equilibrium problems, solving a family of quasi- $\varphi$-asymptotically nonexpansive mappings, and obtaining common fixed points in Banach space," International Journal of Mathematics and Mathematical Sciences, vol. 2011, Article ID 106323, 16 pages, 2011. 
[28] I. Cioranescu, Geometry of Banach Spaces, Duality Mappings and Nonlinear Problems, vol. 62 of Mathematics and Its Applications, Kluwer Academic Publishers, Dordrecht, The Netherlands, 1990.

[29] W. Takahashi, Nonlinear Functional Analysis, Yokohama Publishers, Yokohama, Japan, 2000, Fixed Point Theory and Its Applications.

[30] Y. I. Alber, "Metric and generalized projection operators in Banach spaces: properties and applications," in Theory and Applications of Nonlinear Operators of Accretive and Monotone Type, vol. 178 of Lecture Notes in Pure and Applied Mathematics, pp. 15-50, Dekker, New York, NY, USA, 1996.

[31] S. Kamimura and W. Takahashi, "Strong convergence of a proximal-type algorithm in a Banach space," SIAM Journal on Optimization, vol. 13, no. 3, pp. 938-945, 2002. 


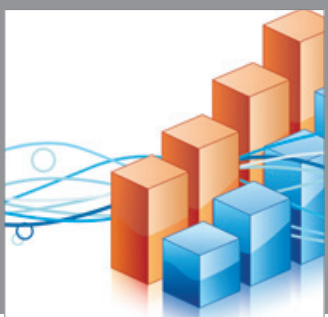

Advances in

Operations Research

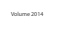

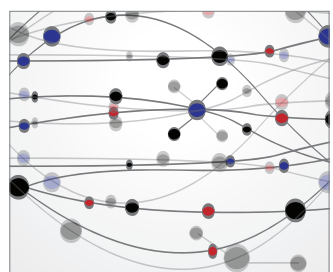

\section{The Scientific} World Journal
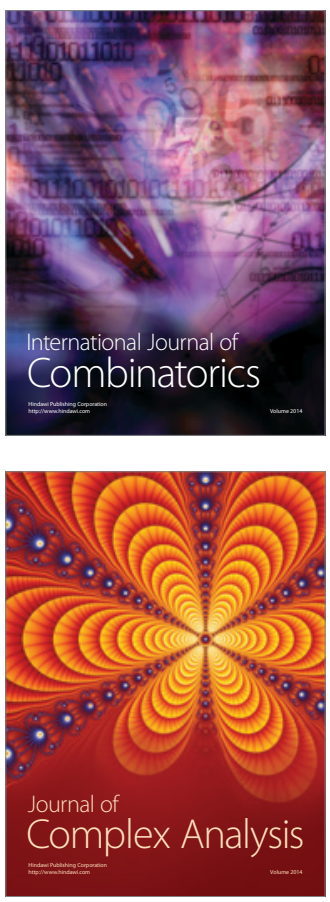

International Journal of

Mathematics and

Mathematical

Sciences
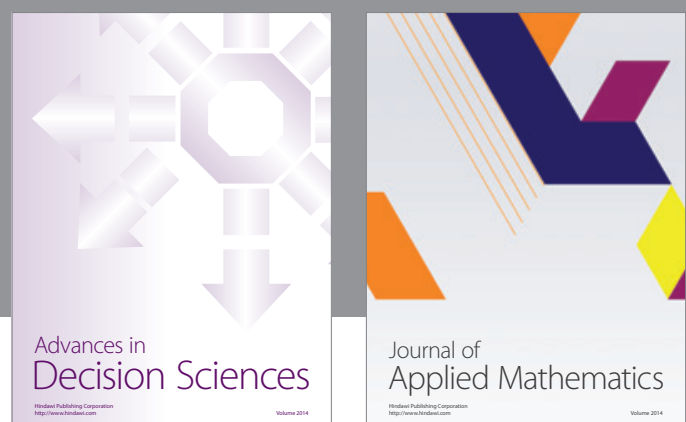

Journal of

Applied Mathematics
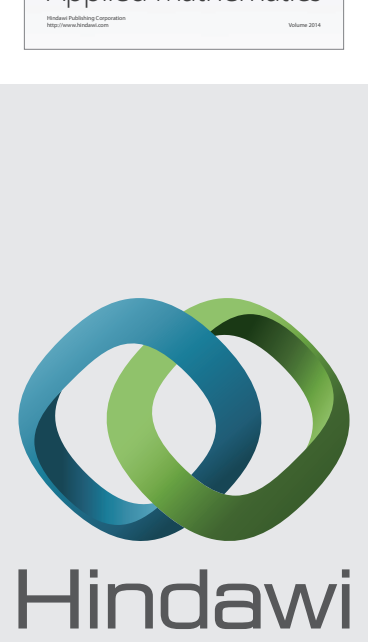

Submit your manuscripts at http://www.hindawi.com
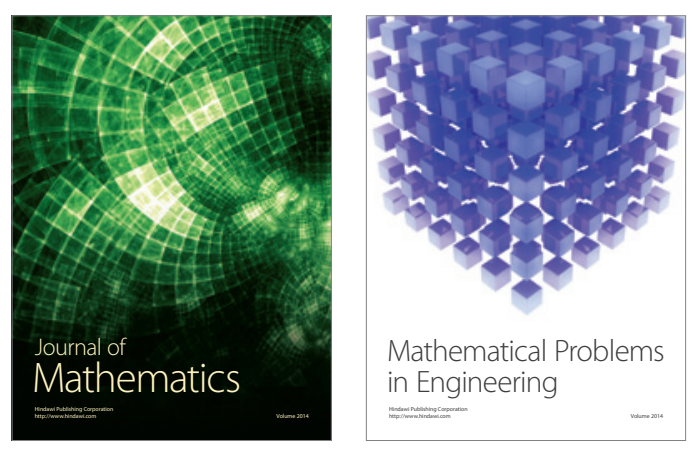

Mathematical Problems in Engineering
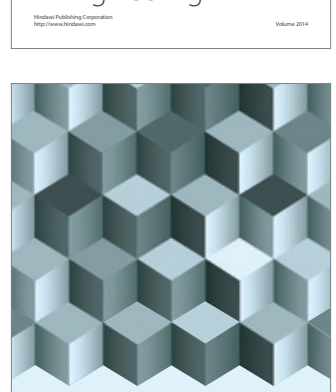

Journal of

Function Spaces
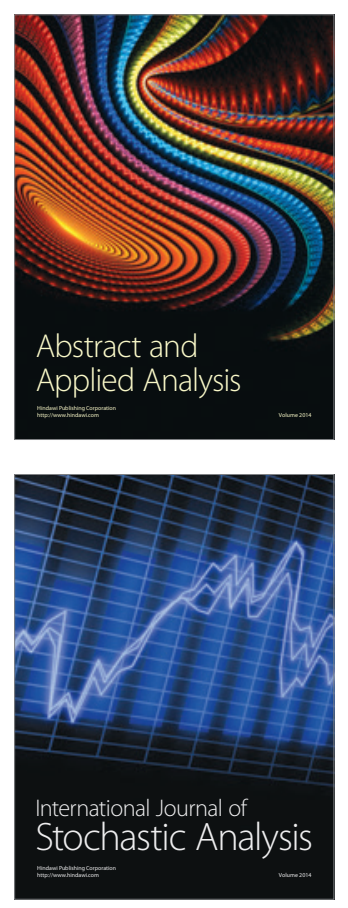

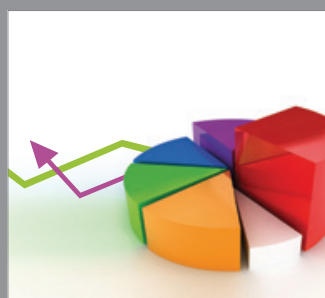

ournal of

Probability and Statistics

Promensencen
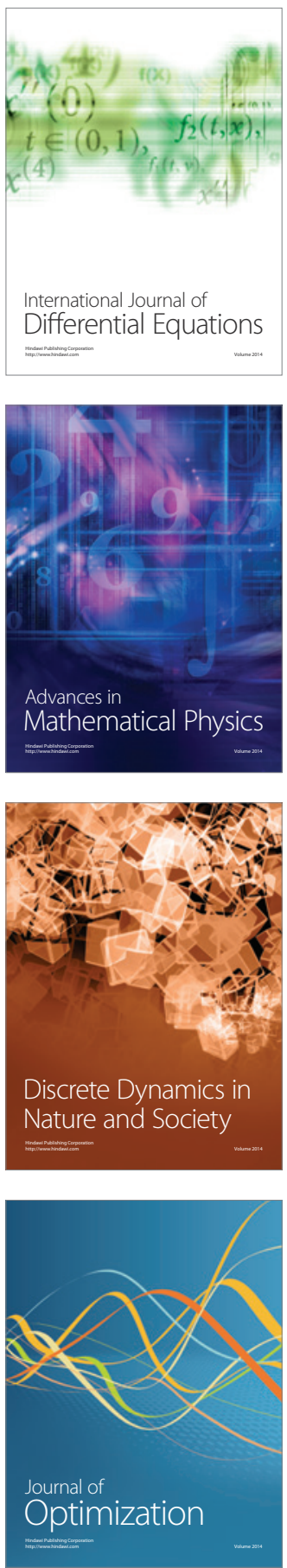